\title{
Reflection and Exploration of Traditional Culture Value in Artistic Design
}

\author{
Xiaoguang Wang \\ NanJing City Vocational College (Nanjing Radio and Television University), Nanjing 210038, China \\ ncywxg@163.com
}

Keywords: artistic design, traditional culture, culture and idea, change, innovation.

\begin{abstract}
This article mainly discusses the lack of traditional culture and idea in modern Chinese artistic design, analyzes the reasons for the problem, and then analyzes the importance of traditional Chinese culture to artistic design. This paper expounds how to coordinate the traditional and modern design, how to integrate the tradition into the modern design, and how to truly design a design with Chinese characteristics. Focus on the analysis of the role of Chinese traditional culture on the design and explore how the artistic design can show the Chinese traditional characteristics and nationality and carry forward the excellent Chinese tradition in the design.
\end{abstract}

\section{Chinese Modern Artistic Design Lack Traditional Chinese Culture and Local Traditional Culture Has Low Concern}

The Chinese nation has a long history, and the same artistic design has a long period of development. Since twenty-first Century, with the development of the reform and opening up, more and more advanced foreign design ideas and ideas, such as the introduction of modernism and postmodernism, are more obvious in Chinese artistic design. At the same time, we find that more and more modern Chinese designers are addicted to the so-called "international style" and "fashion trend" style, but the attention to Chinese traditional culture is declining, and even many designers have a totally negative attitude towards the modern design of Chinese traditional culture. They think tradition is not popular, there is no market for tradition.

The author thinks that this is a very wrong point of view. Chinese culture has a long history, and in thousands of years of culture, it is the excellent tradition and essence of the nation. As a contemporary designer, the advanced design methods of foreign countries should be combined with the traditional Chinese culture and ideas. Only in this way can we create excellent national artistic design works that are consistent with the Chinese nation and represent China's outstanding art and design works with national characteristics. The Chinese nation can represent China's outstanding artistic design works with national characteristics. The so-called "national is the world", the traditional Chinese culture is more and more emphasized and studied by foreign designers. It has to be said that Chinese traditional culture has been seriously missing in the design. This phenomenon will seriously impede the development of China's future design.

\section{Organization of the Text Chinese Traditional and Modern Design is Not a Contradictory Relationship, But a Dialectical Relationship of Mutual Influence and Common Development}

Many designers think that tradition and modernity are contradictory to each other. The fact is not the case. Modern is the inheritance and development of the tradition, and the tradition is the foundation of the modern development. They are mutual influence and common development relationship. Traditional ideas and culture exert a subtle influence on modern design. Now there are many designers who define themselves as "anti-traditional designers". They think that their artistic design is derived from modern, and that all things related to tradition are abandoned. In fact, this is a very wrong idea. It is only an organic combination of Chinese traditional culture and ideas with the artistic design of the present generation. Only with the organic combination of Chinese traditional 
culture and thought and modern artistic design can we create artistic design which is more in line with the aesthetic and requirements of the people of our nation.

We look around the internationally designed successful countries, such as Europe and Japan, we will be surprised to find that the good artistic designs that are recognized by the world are actually more derived from there creation of the nation and the local traditional culture. Their design works are very good to inherit and develop the tradition. We can't create some new design works out of thin air. In particular Japan, when we have already demolished some old houses and a lot of new reinforced concrete buildings were built. In China, more and more traditional craftsmen are struggling to make a living. They worship traditional craft and craftsman spirit. The combination of traditional technology and modern design has created more and more excellent design works with Japanese national characteristics and culture.

Therefore, we can see that the way out for Chinese design is not to be found out form "foreign", but that we need to carefully examine ourselves and respect the tradition from the traditional cultural thought of our nation to find a way out and breakthrough. Only by combining Chinese traditional and modern design can we truly create outstanding artistic design works recognized by the world. For example, the successful case of the "Wanke fifth garden" is a good proof of this. The design of the "fifth garden" has used and used many traditional ideas and gardening techniques in traditional Chinese gardens, and a lot of traditional garden styles are innovated and changed, which makes the whole design have the Chinese traditional aesthetic charm. It also has a very modern sense and a sense of the times.

\section{Reflection and Exploration of Traditional Culture and Thought in Artistic Design}

The Chinese traditional culture and thought play a very important role in the artistic design. The author thinks that the Chinese design can only create the design to truly suitable for the Chinese people by inheriting the traditional culture and thought. Modern artistic design should fully reflect the value of traditional culture and thought and use the essence of Chinese traditional culture to create excellent works with national characteristics and innovation.

\subsection{Respect Traditional Culture and Ideology and Truly Understand the Essence of Our Traditional Culture and Thoughts}

If we want to integrate traditional Chinese culture and ideas into our art and design correctly, we must first respect traditional culture and ideology. To be truly aware of the importance of traditional culture and thought, not a superficial search for some traditional "fragments", for example, many designers have used some traditional elements and styles in their works, and simply think that this is the traditional Chinese design.

In view of the history of China's design and development, we will find that Chinese traditional culture and thought are constantly updated and changed with the development of the times, while the essence and connotation of culture and thought are invariable. Only by excluding those superficial phenomena and studying their essence can we grasp the essence and connotation of Chinese traditional culture. Only on this basis can we integrate traditional culture and ideas into design in the process of modern design, which can reflect the value of traditional culture.

We should study conscientiously on the basis of respect for tradition, learn from the traditional development and the characteristics of each time, and really "understand" Chinese traditional culture and thought, can we find out the valuable ideas of modern design. Looking at the course of art and design in University, most of the courses are for the study of modern design methods. The learning of traditional design thinking and culture is relatively less, and the corresponding courses and hours should be added. Only in this way can the future designers understand the traditional Chinese culture and ideas in a comprehensive way. In order to truly understand the traditional culture and ideology, we can truly realize the importance of Chinese tradition, so that we can in the design of the overall use of the use and grasp. 


\subsection{For Traditional Inheritance and Innovation, It Is Not Only the Form but Also the Deep Grasp and Application}

Now there are some designers carry out artistic design in the name of tradition. They proclaim that their design is a creative design based on the combination of traditional and modern. In fact, most of the designers just do a lot of "surface articles". They are designed in the name of the traditional. For tradition, they are basically a smattering of knowledge, or even to cater to domestic demand for commercialized propaganda. The design like this is also common in China. Chinese traditional ideas and cultures have high philosophical ideas and ideas. It has been developed for a long time and is not a superficial "plagiarism" in the so-called "traditional design".

Many designs are copied by copying some traditional copy patterns into design. It is considered that this is the inheritance and development of the tradition, and that it is the combination of traditional and modern design. In fact, Chinese traditional design ideas and culture are created in the process of living in pursuit of harmony between man and nature in life. This tradition is not a fixed style or shape, but a pursuit for a better life, an "initial heart" in artistic design, and a guiding principle and thought. We only need to truly understand the essence of the deep form through the representation of shapes and patterns, so that we can know what the real tradition is. Our design can reflect traditional culture and ideology, so that we can really apply tradition to design.

\subsection{Tradition is Both a "Changeless" and a "Change"}

The modern design wants to embody the value of the traditional cultural thought and needs to seize the "invariable" in the traditional culture. The author thinks that the same is the pursuit of the traditional culture, the attitude of life, the angle and the way of looking at the problem, and we should inherit the traditional thought and philosophy between man and nature, between people and people.

There is a great difference between Chinese traditional thought and Western thought. Chinese traditional thought believes that people should conform to the law of natural development and people should respect nature. This is the idea of "theory that man is an integral part of nature ", while the West believes that man will conquer nature, and Human beings need to overcome nature and transform nature. In modern artistic design, we should follow the essence of "theory that man is an integral part of nature", that is, our design should respect "nature", conform to "nature" and use "nature", and the design should come from "nature" and return to "nature". In essence, design is for human and nature. Nature refers to the space and environment we live in. This is the essence of Chinese traditional culture and thought.

Tradition is not fixed, it will change with the development of the times. We can't use a "frame" to "frame" the traditional "die", the traditional definition of a style and form, for the sake of tradition, to simply imitate the style and style of the past. For example, many of the design is a simple copy of the traditional architectural style, that is, the so-called "fake ancient construction", even more of the new buildings to do old treatment, to make it look like a building with a certain age, I think this practice is very undesirable.

With the development of history, it can be seen that our traditions and ideas are also changed and developed, and the corresponding modern design should also follow this rule. Modern design needs to destroy the old and establish the new, need continuous innovation, with the development of new materials, new technology, new way of life and so on, modern design calls for certain responses to these new products. Modern design can use new materials, new technology, new technology and new means to solve all kinds of problems in modern people's new life style.

The author thinks that the inheritance of traditional design should be more ideological, and the traditional Chinese design ideas are applied to modern design. Only in this way can we create artistic design with traditional characteristics in line with modern needs. For example, when I.M.Pei designed the Suzhou Museum, the most important thing to consider in the design is to carry out the innovation of modern people and nature on the basis of the inheritance of traditional culture and thought. The Suzhou museum is not a superficial copy of the traditional style and modeling, but the use of traditional design ideas to guide the design practice, the use of modern materials and technology to make an interpretation of the traditional culture and thought innovation. 
It is impressive that many people suggest that he use Chinese traditional tiles when building roofs. He analyzed the shortcomings of traditional tiles, innovative the use of new materials and processes instead of traditional tile roofs. Form and color have certain echoes with traditional tiles, but in function, they are more suitable for human and environment than traditional tiles. I.M.Pei through the traditional development and innovation, the design of Suzhou museum is finally successful.

\section{Summary}

To sum up, artistic design wants to reflect the value of traditional culture and thought. First of all, we need to reexamine the "tradition" and excavate the deep connotation of traditional culture and thought. A simple cognitive tradition must not really combine traditional culture with modern design. Secondly, we should recognize the "change" and "changeless" of traditional culture, continue to Persisting and carrying forward the traditional "constant" factors. At the same time, we should fully seize the characteristics of "change" to innovate, and use modern technology, materials to combine modern environment and the needs of modern people to create the design of Chinese characteristics.

\section{Acknowledgments}

This paper is a series of achievements in the research project of philosophy and sociology in Jiangsu universities. Project Name: Color Research of Chinese traditional architecture under the background of "China dream". Project approval number: 2015SJD329.

\section{References}

[1]. Wang Xiaoguang1, Qi Fei2, et al. The inspiration of Chinese traditional architectural color to the modern design under the background of "Chinese dream". 2017 2nd International Conference on Education, Sports, Arts and Management Engineering (ICESAME 2017). China Zhengzhou, 2017-04-29, p.271-274.

[2]. Fan Lingyan, et al. On the inheritance of Chinese traditional culture in modern interior design. Research in Educational Development. Phase S1(2017), p. 120-122.

[3]. Liu Fang, et al. The inheritance and development of traditional culture in modern interior design. Art Education Research. Phase 20(2017), p.53.

[4]. Tian Chenxi, et al. The integration of traditional culture in modern environmental art design. Home Drama. Phase15(2016) p.183-185.

[5]. Hui Bao1, Le Lvxi2, Han Shuding3, et al. Traditional cultural conception in modern environmental art design. Sichuan Cement. Phase 01(2017) p.71. 